\title{
Prevalence of Diabetes Mellitus Disease and its Association with Level of Education Among Adult Patients Attending at Dilla Referral Hospital, Ethiopia
}

\section{Fekadu Alemu*}

Department of Biology, College of Natural and Computational Sciences, Dilla University, P.O. Box 419, Dilla, Ethiopia

\begin{abstract}
Diabetes mellitus is becoming one of the major health problems in the developing countries. As the International Diabetes Federation suggests that the number of adults living with diabetes worldwide was increasing from time to time. The aim of this study is to assess the educational level of Diabetic patients as well as service given to them and the frequency of the disease over last four years at Dilla Referral Hospital. Data was collected through self administer/interviewer administer questionnaire and document review. According to this finding more exposure to diabetes disease, it must be was found an illiterate individuals $15(37.50 \%)$ followed by Primary school, College and University level individuals $9(22.50 \%), 6(15.00 \%), 5(12.50 \%)$ respectively. Diabetes type II diseases were highly prevalent across the year than Diabetes type I. The prevalence of diabetes mellitus is increasing and type II is more predominate than type I at Dilla Referral Hospital. Therefore, appropriate actions need to be taken to provide access like education and treatment in order to reduce associated complications.
\end{abstract}

Keywords: Diabetes mellitus; Diabetes type I; Diabetes type II; Dilla referral hospital

\section{Introduction}

Diabetes Mellitus (DM) is defined as a cluster of metabolic disorders, characterized by hyperglycemia high enough to significantly increase the incidence of a specific an unique type of microangiopathy (retinopathy, nephropathy and neuropathy) $[1,2]$. DM is a chronic metabolic disorder that represents a serious public health concern. It is characterized by defective insulin secretion or deficiencies in the action of insulin. The prevalence of diabetes mellitus has now reached epidemic proportions in both developed and developing countries, affecting more than 366 million people suffer from DM and the number is expected to rise to 552 million by 2030 [3]. The incidence of diabetes worldwide is now estimated to be around 366 million, far beyond the 285 million projected by the World Health Organization (WHO) for 2010 from global statistics gathered in 2008 [4]. International Diabetes Most of this increase will occur as a result of $150 \%$ rise in developing countries. This number is likely to increase in the coming years as a result of an ageing global population, urbanization, rising prevalence of obesity and sedentary lifestyles. It is estimated that developing countries will bear the brunt of DM epidemic to the extent of $77 \%$ of the global burden in the $21^{\text {st }}$ century as a result of population growth, ageing, unhealthy diets, obesity and sedentary lifestyles [5].

Type 1 diabetes mellitus (T1DM) is one of the most common endocrine and metabolic conditions in childhood. Data from large epidemiological studies worldwide indicate that on an annual basis, the overall increase in the incidence of T1DM is around $3 \%$ and about 78,000 children under age 15 years develop T1DM worldwide [3]. Environmental factors have long been implicated in the pathogenesis of T1DM both as initiator and potentiators of pancreatic $\beta$-cells destruction [6].

Type 2 Diabetes mellitus (T2DM) is a metabolic disorder characterized by the presence of chronic hyperglycemia, which results from resistance to insulin actions on peripheral tissues as well as inadequate secretion of insulin [7] and an impaired suppression of glucagon secretion in response to ingested glucose. Thus, T2DM involves at least two primary pathogenic mechanisms: (a) a progressive decline in pancreatic islet cell function resulting in reduced insulin secretion and inadequate suppression of glucagon secretion $[8,9]$ and $(b)$ peripheral insulin resistance resulting in a decrease in the metabolic responses to insulin (American Diabetes Association, 2010). The resulting insulin deficiency disrupts the regulation of glucose production in the liver and is a clue element in the pathogenesis of glucose intolerance [10]. Type 2 diabetes mellitus is a complex metabolic disorder of heterogeneous etiology with social, behavioral, and environmental risk factors unmasking the effects of genetic susceptibility [11]. There is a strong hereditary (likely multigenic) component to the disease, with the role of genetic determinants illustrated when differences in the prevalence of type 2 diabetes mellitus in various racial groups are considered [12]

Diabetes affects virtually every organ system in the body and the duration and severity of the disease may have a direct impact on organ involvement. Diabetes Mellitus (DM) is a chronic progressive metabolic disorder characterized by hyperglycemia mainly due to absolute (Type $1 \mathrm{DM}$ ) or relative (Type $2 \mathrm{DM}$ ) deficiency of insulin hormone [1]. DM virtually affects every system of the body mainly due to metabolic disturbances caused by hyperglycemia, especially if diabetes control over a period of time proves to be suboptimal [1]. Diabetes mellitus is associated with a wide range of circulatory manifestations such as alterations in endothelial function and cardiovascular disease [13,14]. Most of the complications in diabetes are due to hyperglycaemia and increased generation of oxygen derived free radicals, which may lead

*Corresponding author: Fekadu Alemu, Department of Biology, College of Natural and Computational Sciences, Dilla University, P.O.Box. 419, Dilla, Ethiopia, Tel: +251920839215; E-mail: fekealex@gmail.com

Received December 03, 2014; Accepted February 28, 2015; Published March 03, 2015

Citation: Alemu F (2015) Prevalence of Diabetes Mellitus Disease and its Association with Level of Education Among Adult Patients Attending at Dilla Referral Hospital, Ethiopia. J Diabetes Metab 6: 521. doi:10.4172/2155-6156.1000521

Copyright: (c) 2015 Alemu F. This is an open-access article distributed under the terms of the Creative Commons Attribution License, which permits unrestricted use, distribution, and reproduction in any medium, provided the original author and source are credited. 
to vascular dysfunction $[15,16]$. Long term diabetes is associated with several co-morbidities, such as erectile dysfunction, blindness, poor wound healing, kidney failure, heart disease, etc; as a result of considerable damage, dysfunction, and failure of various organs that develop as the disease progresses [17].

Ethiopia is the second most populous country in sub-Saharan Africa where more than $80 \%$ of the population lives in the country side. The country experiences a heavy burden of disease mainly attributed to communicable infectious diseases and nutritional deficiencies. Currently, Ethiopia is also challenged by the growing magnitude of chronic non communicable diseases. Despite major progresses in education, the literacy status of the population of Ethiopia is still low with total adult literacy rate of $36 \%$ (62\% for male and $39 \%$ for female).The education level in the country is still a significantly marker influencing the spread of disease, shaping the health seeking behavior of individuals and communities including the utilization of modern health care service (http://www.moh.gov.et/; http://www.ethiomedic. $\operatorname{com} /)$.

The estimated prevalence of DM in adult population of Ethiopia is $1.9 \%[18,19]$. Furthermore the prevalence of diabetes among older subjects in Ethiopian (age $>40$ years) was higher (2.4\%) [20]. According Megerssa et al. [21] was reported that on diabetic patients in Ethiopia, $62.3 \%$ were males and $37.7 \%$ females and the age ranged from 20 to 70 years old. Moreover, Cohen et al reported a high prevalence of diabetes (8.9\%) among young (age $<30$ years) Ethiopian Jews who have been to Israel for less than 4 years [22]. WHO estimated the number of diabetic cases in Ethiopia to be 800,000 by the year 2000, and the number is expected to increase to 1.8 million by 2030 [23] Diabetes mellitus is emerging as one of the major chronic health problems in Ethiopia, although its incidence and prevalence are still unknown in the general population [24]. In Ethiopia, national data on prevalence and incidence of DM are lacking. However, patient attendance rates and medical admissions in hospitals are rising [25].

In addition IDFA reported Ethiopia to be ranked $3^{\text {rd }}$ among the ten top countries in Africa with 1.4 million DM cases and estimated prevalence of $3.32 \%$ by year 2012 . World Health Organization (WHO) estimated in 2011 [26] that $34 \%$ of Ethiopian population is dying from non-communicable diseases, with a national cardiovascular disease prevalence of $15 \%$, cancer and chronic obstructive pulmonary disease prevalence of $4 \%$ each, and diabetes mellitus prevalence of $2 \%$. Data on DM are scarce in Ethiopia. Most clinical data are not timely reviewed and made available for decision makers. This paper tries to show the trend in the burden of DM in the Ethiopian context, which is crucial input for planning health services for the needy and preventing premature adult deaths $[27,28]$. Despite the above estimations for global prevalence of the four major non-communicable diseases, cardiovascular disease, cancer, diabetes mellitus, and chronic obstructive pulmonary disease were not well-documented in Ethiopia. On the other hand, accurate information on the prevalence of major public-health importance is required to have informed health policy decision $[29,30]$. Therefore, it is crucial to document prevalence estimations for the major noncommunicable diseases for the purposes of research and interventions. Purpose of this study is to assess the educational level of Diabetic patients as well as service given to them and the frequency of the disease over last four years at Dilla Referral Hospital.

\section{Material and Methods}

\section{Description of the study area}

This study was conducted at Dilla Referral Hospital where found in
Gedeo zone in the south west of the Country, Ethiopia. It was far 359 $\mathrm{Km}$ from South of city of Ethiopia (Addis Ababa). The town is found on altitude of 1300-300 meter above sea level and climate condition is weynadega and it average rain fall is from 760-1700 meter/year. The geographical location on the town lies between $7{ }^{\prime} 39$ north latitude and $35^{\prime} 24$ to $37^{\prime} 90$ East longitude. The town is surrounded in North by Sidama, in South by Wenago, in east by Bale Oromiya and West by Oromiya Regional state. The study was conducted from November to July 2014.

\section{Study design}

The study was designed to get information on assessment of medical and social assistance for diabetic patients attending Dilla Referral Hospital.

\section{Study population}

The study population was diabetic patients who visited Dilla Referral Hospital from 2011 to 2014 year. The study population and sample size were patients who visited (diagnosed) at Dilla Referral Hospital. The total number of sample size was 40 diabetic patients which are interviewed.

\section{Sampling technique}

This study was used the simple random sampling methods to get real, relevant and detail information from diabetic patients who are follow up at Dilla referral hospital.

\section{Data collection and Source of data}

The secondary data was obtained from Dilla Referral Hospital from registration documents. These documents were consist diabetic patients history from 2011 to 2014 year. The data was organized with respect to age and sex group. Around 40 diabetic patients were interviewed and 40 questionnaires were distributed and recollected after being filled by diabetic patients excluding uneducated patients.

\section{Ethical clearance}

The study protocol was reviewed and ethically approved by Dilla University ethical and clearance committee. Before data collection, an informed consent was obtained from respondents. The confidentiality of the respondents was maintained.

\section{Data analysis}

Data entry and analysis was performed using the statistical package for Social Sciences for Windows SPSS (version 16.0). For analysis of the percentage and total diabetic patients were follow up at Dilla Referral Hospital. The results were expressed graphically and as tabular.

\section{Results}

\section{Characteristics of the study}

Out of the total 40 study participants planned where $23(57.50 \%)$ were female and the remaining $17(42.50 \%)$ were male. The age ranges were 15-49 all participate. More than half (57.50\%) of them were female.

\section{Level of education among diabetic patients}

Education status had a significant association with Diabetes risk factor. Because according to this finding more exposure to diabetes disease were found on an illiterate individuals 15 (37.50\%) followed by Primary school, College and University level individuals 9 (22.50\%), 6 (15.00\%), 5 (12.50\%) respectively as indicated in the Table 1. 
Citation: Alemu F (2015) Prevalence of Diabetes Mellitus Disease and its Association with Level of Education Among Adult Patients Attending at Dilla Referral Hospital, Ethiopia. J Diabetes Metab 6: 521. doi:10.4172/2155-6156.1000521

Page 3 of 5

\section{Service given towards diabetic patients at dilla referral hospital}

Twenty six $(65.00 \%)$ of the study participants had to evaluate assistance were good and around $(22.50 \%)$ were not effective. Eighteen $(45.00 \%)$ of the study participants were faced to a problem during appointed to follow up at Dilla Referral Hospital as well as more than half (55.00\%) of the study participants did not faced any problem when they were appointed to follow up their health status at this Hospital as indicted in Table 2.

According to the secondary data obtained from Dilla Referral Hospital, indicated the diabetic patients were increased across the year 2011-2014 as indicated in Table 3.

As indicated in the Figure 1 the type of diabetes disease prevalence of among the males were $50.00 \%$ type II followed by type I $(20.00 \%)$ in 2011.

As indicated in the Figure 2 the type of diabetes disease prevalence of among the female, type II diabetic disease were highly predominant than type I diabetic disease.

As indicated in the Figure 3 the number of diabetic patients were increased from 2011-2014 at Dilla Referral Hospital.

\section{Discussion}

According the results showed that educational status had significant association with good practice like that of knowledge. This finding was showed that more diabetic patients were an illiterate individuals followed by Primary school, College and University level of education. According Megerssa et al. [21] had reported on Diabetic patients in Ethiopia, education profile of the participants who respond showed $57 \%(n=232)$ of the participants had primary or secondary education, the remaining $43 \%(n=175)$ had college or university education. This finding was consistent with study in Egypt [31]. This could be attributed that participant who had education have good chance to modify their life style and their health status by finding different alternatives for checkup. Educated people may also have better income better income status. This could also be their accessibility for manual of dietary management, weight reduction increases. According Megerssa et al. [21] had reported on modifable and non modifable risk factors for diabetic disease in Ethiopia, in modifable risk factors relatively higher prevalence of undiagnosed DM was observed in those overweighed (9.76\%), higher WC $(9.88 \%)$, ex-smokers $(11.11 \%)$, physically inactive (7.69\%), hypertensive (13.51\%), frequent alcohol drinker (8.64\%), high TC (5.42\%) and high TG level (7.8\%) as compared to their counterparts. In most of the series, prevalence was found to increase with increasing age [32-37]. Most patients (51.2\%) did not realize the importance of screening the other family members for diabetes and according to some literatures this might probably indicates for a large number of people remaining undiagnosed [38].

Lower age was significantly associated with knowledge. This finding was supported by other different literatures $[31,39,40]$ and with

\begin{tabular}{|c|c|c|c|c|c|c|c|}
\hline \multirow{2}{*}{ Sex } & \multirow{2}{*}{ Age category } & \multirow{2}{*}{$\begin{array}{c}\text { Number of diabetes } \\
\text { patient attending at } \\
\text { Dilla Referral Hospital } \\
\text { at } 2014\end{array}$} & \multicolumn{5}{|c|}{ Educational level } \\
\hline & & & Illiterate & Primary school & Secondary school & College & University \\
\hline \multirow{4}{*}{ Male } & $<15$ age & 0 & - & - & - & - & - \\
\hline & $15-49$ age & 16 & \multirow{2}{*}{$7(17.50 \%$} & \multirow{2}{*}{$2(5.00 \%)$} & \multirow{2}{*}{$2(5.00 \%)$} & \multirow{2}{*}{$5(12.50 \%)$} & \multirow{2}{*}{$1(2.50 \%)$} \\
\hline & $>49$ age & 3 & & & & & \\
\hline & Total & 19 & & & & & \\
\hline \multirow{4}{*}{ Female } & $<15$ age & 0 & - & - & - & - & - \\
\hline & $15-49$ age & 19 & \multirow{2}{*}{$8(20.00 \%)$} & \multirow{2}{*}{$7(17.50 \%)$} & \multirow{2}{*}{$3(7.50 \%)$} & \multirow{2}{*}{$1(2.50 \%)$} & \multirow{2}{*}{$4(10.00 \%)$} \\
\hline & $>49$ age & 2 & & & & & \\
\hline & Total & 21 & $15(37.50 \%)$ & $9(22.50 \%)$ & $5(12.50 \%)$ & $6(15.00 \%)$ & $5(12.50 \%)$ \\
\hline
\end{tabular}

Table 1: Frequency of Diabetes Millets patients at each educational level at Dilla Referral Hospital 2014.

\section{Types of questionnaires to the Dilla Referral Hospital attending patients at 2014}

1. How do you evaluate the assistance provide to relief from you?

2. When you are appointed to follow up your health status in the hospital, have you faced problem?

3. Have you faced any problem related with social relationship due to being diabetic patient?

\begin{tabular}{|c|c|c|}
\hline \multirow{2}{*}{$\begin{array}{c}\text { Target answered } \\
\text { questionnaires }\end{array}$} & \multicolumn{2}{|c|}{ Sex } \\
\cline { 2 - 3 } & Male & Female \\
Good & $15(37.50 \%)$ & $11(27.50 \%)$ \\
Bad & $4(10.00 \%)$ & $1(2.50 \%)$ \\
Not effective & $4(10.00 \%)$ & $5(12.50 \%)$ \\
\hline Yes & $10(25.00 \%)$ & $8(20.00 \%)$ \\
No & $12(30.00 \%)$ & $10(25.00 \%)$ \\
\hline Yes & $6(15.00 \%)$ & $3(7.50 \%)$ \\
No & $13(32.50 \%)$ & $14(35.00 \%)$ \\
\hline
\end{tabular}

Table 2: Distributed questionnaires to diabetic patients attending at Dilla Referral Hospital and their response 2014 year.

\begin{tabular}{|c|c|c|c|c|c|}
\hline \multirow{5}{*}{ Year } & \multicolumn{4}{|c|}{ Sex } & \multirow{5}{*}{$\begin{array}{l}\text { Total patients } \\
\text { per year }\end{array}$} \\
\hline & \multicolumn{2}{|c|}{ Male } & \multicolumn{2}{|c|}{ Female } & \\
\hline & \multicolumn{2}{|c|}{ age range $>15$} & \multicolumn{2}{|c|}{ age range $>15$} & \\
\hline & \multicolumn{2}{|c|}{ Types diabetes disease } & \multicolumn{2}{|c|}{ Types diabetes disease } & \\
\hline & Type I & Type II & Type I & Type II & \\
\hline 2011 & $4(20.00 \%)$ & $10(50.00 \%)$ & $1(5.00 \%)$ & $5(25.00 \%)$ & 20 \\
\hline 2012 & $13(26.53 \%)$ & $18(36.73 \%)$ & $6(12.24 \%)$ & $12(24.50 \%)$ & 49 \\
\hline 2013 & $13(15.85 \%)$ & $31(37.80 \%)$ & $11(13.42 \%)$ & $27(32.93 \%)$ & 82 \\
\hline 2014 & $25(7.58 \%)$ & $190(57.57 \%)$ & $30(9.10 \%)$ & $85(25.75 \%)$ & 330 \\
\hline
\end{tabular}

Table 3: Frequency of diabetic disease among each year at Dilla Referral Hospital 2011-2014. 


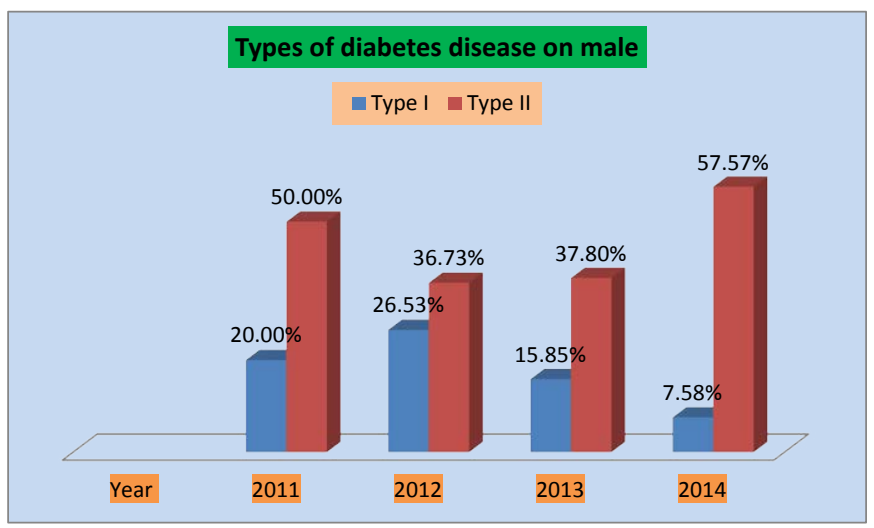

Figure 1: Distribution of type of diabetes among male respondents from data got through document review retrospectively from 2011-2014.

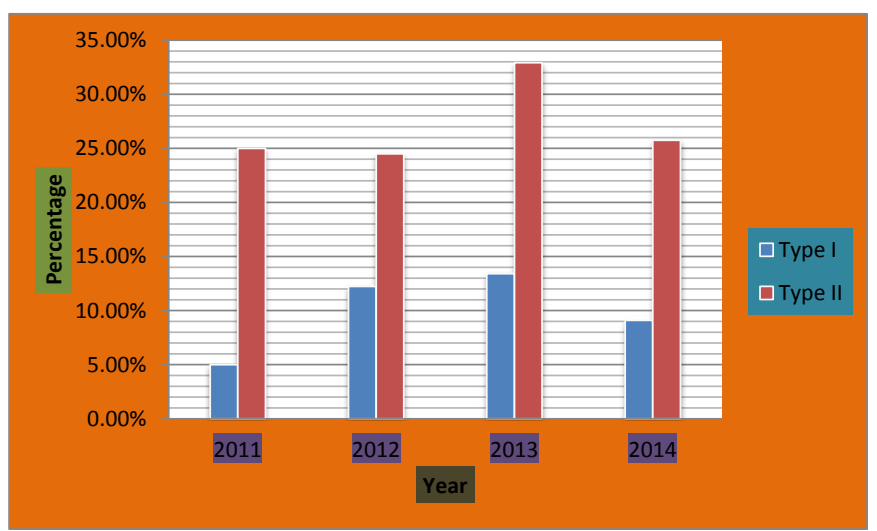

Figure 2: Distribution of type of diabetes among female respondents from data got through document review retrospectively from 2011-2014.

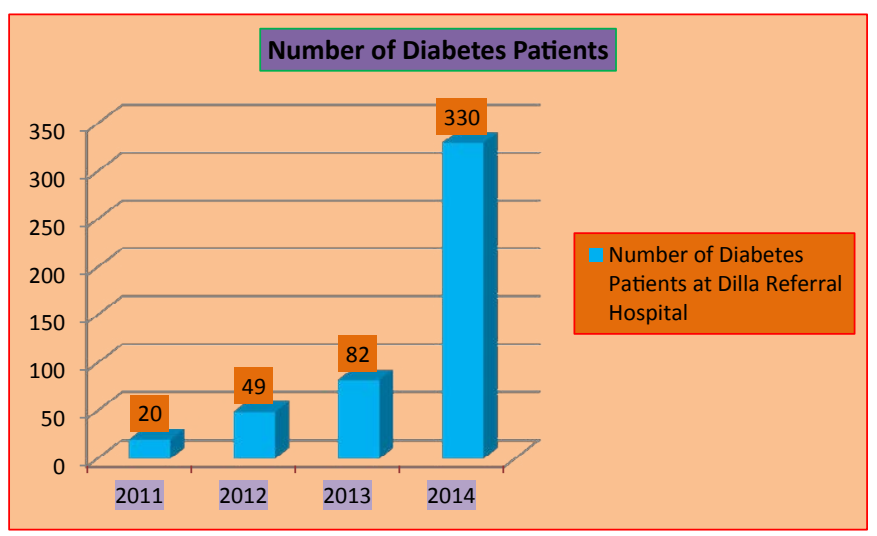

Figure 3: The number of diabetic patients in each year from 2011-2014 at Dilla Referral Hospital.

West and Goldberg principles which reported that a decrease of 3\% in the knowledge score of diabetic patients for every 10 -year increase in age [41]. This could be due to older persons have less education, worse cognitive function and have more co-morbidities, which might lead to confusion [40]. Another explanation might be younger patients were more likely to be more educated, faster in remember and recall and they might be new sufferers of diabetes and they were eager to have more knowledge about their disease [31].

Regarding to the impacts came from social relationship due to being diabetes patients were a little $(22.50 \%)$ while more than half patients $(67.50 \%)$ were not faced any problem came from social relationship due to being diabetes patients. These findings indeed underscore the critical role played by patient awareness and practice of diabetes self management behaviors in improving adherence to drug therapy, ensuring achievement of adequate glycemic control and minimizing the likelihood of diabetic complication $[42,43]$.

Diabetes type II diseases were highly predominated diseases across the year than Diabetes type I from 2011-2014 at Dilla Referral Hospital. Similar finding from Gondar University Teaching Referral Hospital had reporting by Abebe et al. [44], findings show that the proportion of DM patients has significantly increased over the 10 year observation period (2000-2009) in the study hospital for both Type 1 and Type 2 DM.

Type II diabetic disease were highly predominate in all patients at each year from 2011-2014, were 50.00\%, 36.73\%, 37.80\%, and $57.57 \%$ were type II patients, while, $20.00 \%, 26.53 \%, 15.85 \%$ and $7.58 \%$ with type I patients from $2011-2014$ on males. About $65.6 \%$ of the Type 1 DM patients were men while about $51 \%$ of the women had Type $2 \mathrm{DM}$ [44].

The types II slightly increased across the year when it compared with type I diabetic disease on females. There were more Type $1 \mathrm{DM}$ patients in rural areas compared to urban residents, and much more Type $2 \mathrm{DM}$ patients were from urban areas compared to rural areas [44]. However, T1DM was found to be more prevalent in girls than in boys in studies from Ethiopia, Sudan, Nigeria, and Libya [33,45-48].

The numbers of diabetic patients currently were 330 and it was the highest number of patients at 2014 at Dilla Referral Hospital. Similar, Ethiopia is one of the top five countries with the highest number of people affected by DM in (SSA). Previous reports showed that the prevalence of DM in Ethiopia was 2.5\% in the year 2000 and was estimated to rise to $3.5 \%$ by 2030 .

\section{Conclusion}

Diabetes care in developing countries needs to address the specific background of the patients' population, the rate of disease prevalence in study area and social constraints. The frequency of diabetes mellitus disease at Dilla Referral Hospital is increasing steadily. Type II diabetic disease were highly predominate in all patients at each year from 2011214 , were $50.00 \%, 36.73 \%, 37.80 \%$, and $57.57 \%$ were type II patients on males sex. The types II slightly increased across the year when it compared with type I diabetic disease on females. In addition, diabetic patients were increased across the year 2011-2014 at Dilla Referral Hospital. Therefore, this finding calls attention to the urgent need for monitoring diabetes mellitus disease in order to facilitate timely preventive and curative interventions.

\section{Acknowledgments}

The author would like to express heart fully thanks to Dilla Referral Hospital for providing secondary data for this study.

\section{References}

1. WHO (1999) Consultation: Definition, diagnosis and classification of diabetes mellitus and its complications: report of a WHO consultation. Part 1: Diagnosis and classification of diabetes mellitus.Geneva,WHO/NCD/NCS/99.2.

2. WHO (1999) Obesity: preventing and managing the global epidemic: report of a WHO consultation. WHO Technical report series 894 . 
Citation: Alemu F (2015) Prevalence of Diabetes Mellitus Disease and its Association with Level of Education Among Adult Patients Attending at Dilla Referral Hospital, Ethiopia. J Diabetes Metab 6: 521. doi:10.4172/2155-6156.1000521

3. Danaei G, Finucane MM, Lu Y, Singh GM, Cowan MJ, et al. (2011) National, regional, and global trends in fasting plasma glucose and diabetes prevalence since 1980: systematic analysis of health examination surveys and epidemiological studies with 370 country-years and $2 \cdot 7$ million participants. Lancet 378: 31-40.

4. Cho W, Yue K, Leung A (2005) An outline of diabetes mellitus and its treatment by traditional chinese medicine and acupuncture. Journal of Chinese Medicine 78: 29-37.

5. Knip M, Simell O (2012) Environmental triggers of type 1 diabetes. Cold Spring Harb Perspect Med 2: a007690.

6. American Diabetes Association (2010) Diagnosis and classification of diabetes mellitus. Diabetes Care 33: S62-S69.

7. Müller WA, Faloona GR, Aguilar-Parada E, Unger RH (1970) Abnormal alphacell function in diabetes. Response to carbohydrate and protein ingestion. N Engl J Med 283: 109-115

8. Weyer C, Bogardus C, Mott DM, Pratley RE (1999) The natural history of insulin secretory dysfunction and insulin resistance in the pathogenesis of type 2 diabetes mellitus. J Clin Invest 104: 787-794.

9. Gastaldelli A, Ferrannini E, Miyazaki Y, Matsuda M, DeFronzo RA (2004) Beta-cell dysfunction and glucose intolerance: results from the San Antonio metabolism (SAM) study. Diabetologia 47: 31-39.

10. Kiess W, Böttner A, Raile K, Kapellen T, Müller G, et al. (2003) Type 2 diabetes mellitus in children and adolescents: a review from a European perspective. Horm Res 59 Suppl 1: 77-84.

11. Florez JC (2008) Clinical review: the genetics of type 2 diabetes: a realistic appraisal in 2008. J Clin Endocrinol Metab 93: 4633-4642.

12. Hermans MP (2007) Diabetes and the endothelium. Acta Clin Belg 62: 97-101.

13. Kar P, Holt RI (2008) The effect of sulphonylureas on the microvascular and macrovascular complications of diabetes. Cardiovasc Drugs Ther 22: 207-213.

14. Singh PP, Mahadi F, Roy A, Sharma P (2009) Reactive oxygen species reactive nitrogen species and antioxidants in etiopathogenesis of diabetes mellitus type-2. Indian J Clin Biochem 24: 324-342.

15. Kaneto H, Katakami N, Matsuhisa M, Matsuoka TA (2010) Role of reactive oxygen species in the progression of type 2 diabetes and atherosclerosis. Mediators Inflamm 2010: 453892.

16. Nathan DM, Buse JB, Davidson MB (2009) American Diabetes Association, European Association for Study of Diabetes. Medical management of hyperglycemia in type 2 diabetes: a consensus algorithm for the initiation and adjustment of therapy: a consensus statement of the American Diabetes Association and the European Association for the Study of Diabetes. Diabetes Care 32: 193-203.

17. Gill GV, Mbanya JC, Ramaiya KL, Tesfaye S (2009) A sub-Saharan African perspective of diabetes. Diabetologia 52: 8-16.

18. Alemu S, Dessie A, Seid E, Bard E, Lee PT, et al. (2009) Insulin-requiring diabetes in rural Ethiopia: should we reopen the case for malnutrition-related diabetes? Diabetologia 52: 1842-1845.

19. Watkins P, Alemu S (2003) Delivery of diabetes care in rural Ethiopia: an experience from Gondar. Ethiop Med J 41: 9-17.

20. Megerssa YC, Gebre MW, Birru SK, Goshu AR, Tesfaye DY (2013) Prevalence of Undiagnosed Diabetes Mellitus and its Risk Factors in Selected Institutions at Bishoftu Town, East Shoa, Ethiopia. J Diabetes Metab S12: 008.

21. Cohen MP, Stern E, Rusecki Y, Zeidler A (1988) High prevalence of diabetes in young adult Ethiopian immigrants to Israel. Diabetes 37: 824-828.

22. Gul N (2010) Knowledge, attitudes and practices of type 2 diabetic patients. J Ayub Med Coll Abbottabad 22: 128-131.

23. Abdulkadir J, Reja A (2001) Management of diabetes mellitus: coping with limited facilities. Ethiop Med J 39: 349-365.

24. Tamiru S, Alemseged F (2010) Risk Factors for Cardiovascular Diseases among Diabetic Patients In Southwest Ethiopia. Ethiop J Health Sci 20: 121128.

25. Azevedo M, Alla S (2008) Diabetes in sub-saharan Africa: kenya, mali, mozambique, Nigeria, South Africa and zambia. Int J Diabetes Dev Ctries 28: 101-108.
26. Sharma MK, Kumar D (2008) Health Care Utilization Pattern For Communicable And Non-Communicable Diseases In A Tertiary Care Health Facility In Chandigarh, India. The Internet Journal of Health 7.

27. Dalal S, Beunza JJ, Volmink J, Adebamowo C, Bajunirwe F, et al. (2011) Non-communicable diseases in sub-Saharan Africa: what we know now. Int $J$ Epidemiol 40: 885-901.

28. Giles WH (2010) Preventing non-communicable diseases in sub-Saharan Africa. Glob Health Promot 17: 3-5, 53-6, 92-7.

29. Naglaa MA, Mohamed EM (2010) Effectiveness of Health Education Program for Type 2 Diabetes Mellitus Patients Attending Zigzag University Diabetes Clinic, Egypt. Egypt Public Health Assoc 85: 4.

30. Swai AB, Lutale JL, McLarty DG (1993) Prospective study of incidence of juvenile diabetes mellitus over 10 years in Dar es Salaam, Tanzania. BMJ 306 : 1570-1572.

31. Elamin A, Omer MI, Hofvander Y, Tuvemo T (1989) Prevalence of IDDM in schoolchildren in Khartoum, Sudan. Diabetes Care 12: 430-432.

32. Afoke AO, Ejeh NM, Nwonu EN, Okafor CO, Udeh NJ, et al. (1992) Prevalence and clinical picture of IDDM in Nigerian Igbo schoolchildren. Diabetes Care 15: 1310-1312.

33. Ben Khalifa F, Mekaouar A, Taktak S, Hamhoum M, Jebara H, et al (1997) A five-year study of the incidence of insulin-dependent diabetes mellitus in young Tunisians (preliminary results). Diabetes Metab 23: 395-401.

34. Bessaoud K, Boudraa G, Deschamps I, Hors J, Benbouabdallah M, et al. (1990) [Epidemiology of juvenile insulin-dependent diabetes in Algeria (Wilaya of Oran)]. Rev Epidemiol Sante Publique 38: 91-99.

35. Vos C, Reeser HM, Hirasing RA, Bruining GJ (1997) Confirmation of high incidence of type (insulin-dependent) diabetes mellitus in Moroccan children in The Netherlands. Diabet Med 14: 397-400.

36. Abera E (2000) Patterns of chronic complications of diabetic patients in Menelik II Hospital, Ethiopia. Ethiop J Health dev 14: 113-116.

37. Moodley L, Rambiritch V (2007) An assessment of the level of knowledge about diabetes mellitus among diabetic patients in a primary healthcare setting. SA Fam Practice 49

38. Maxwell O, Cletus N, Chinwe V, Jegberime M, Obinna P (2009) Diabetes selfcare knowledge among type 2 diabetic outpatients in south-eastern Nigeria. Int J Drug Dev Res 1: 85

39. West JD, Goldberg KL (2002) Diabetes self-care knowledge among outpatients at a Veterans Affairs medical center. Am J Health Syst Pharm 59: 849-852.

40. Glasgow RE, Hampson SE, Strycker LA, Ruggiero L (1997) Personal-mode beliefs and social-environmental barriers related to diabetes self-management. Diabetes Care 20: 556-561.

41. Day JL (2000) Diabetic patient education: determinants of success. Diabetes Metab Res Rev 16 Suppl 1: S70-74.

42. Abebe SM, Berhane Y, Worku A, Alemu S (2013) Increasing Trends of Diabetes Mellitus and Body Weight: A Ten Year Observation at Gondar University Teaching Referral Hospital, Northwest Ethiopia. PLoS ONE 8: e60081.

43. Elamin A, Omer MI, Zein K, Tuvemo T (1992) Epidemiology of childhood type diabetes in Sudan, 1987-1990. Diabetes Care 15: 1556-1559.

44. Lester FT (1986) Childhood diabetes mellitus in Ethiopians. Diabet Med 3: 278280.

45. Bella AF (1992) A prospective study of insulin-dependent diabetic Nigerian Africans. J Natl Med Assoc 84: 126-128.

46. Kadiki OA, Reddy MR, Marzouk AA (1996) Incidence of insulin-dependent diabetes (IDDM) and non-insulin-dependent diabetes (NIDDM) (0-34 years at onset) in Benghazi, Libya. Diabetes Res Clin Pract 32: 165-173.

47. Whiting DR, Guariguata L, Weil C, Shaw J (2011) IDF diabetes atlas: global estimates of the prevalence of diabetes for 2011 and 2030. Diabetes Res Clin Pract 94: 311-321.

48. Motala AA, Mbanya JC, Ramaiya KL (2009) Metabolic syndrome in subSaharan Africa. Ethn Dis 19: S2-8-10. 